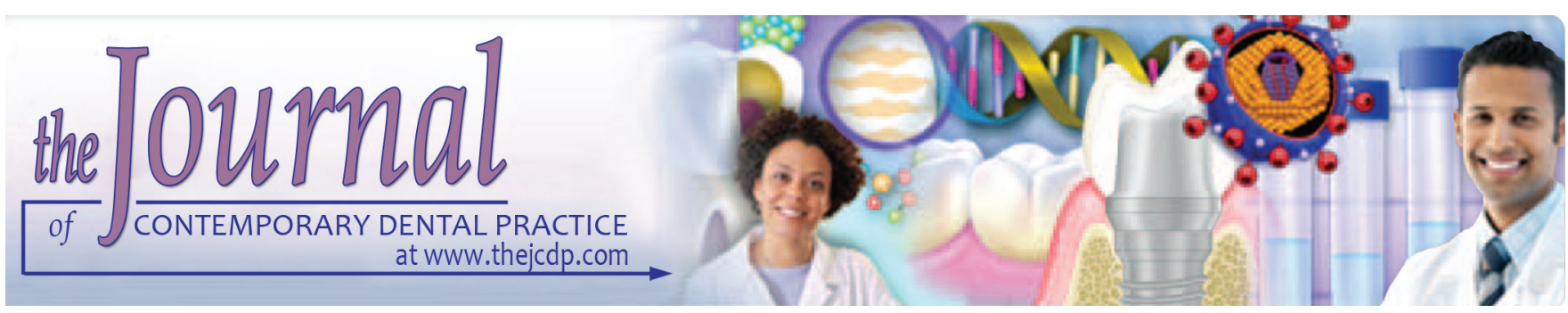

\title{
Evaluation of the Efficacy of Guava Extract as an Antimicrobial Agent on Periodontal Pathogens
}

\author{
${ }^{1}$ Y Sunaina Shetty, ${ }^{2}$ Rajesh Shankarapillai, ${ }^{3}$ Gopinath Vivekanandan, ${ }^{4}$ Raghavendra M Shetty, ${ }^{5}$ Challa S Reddy \\ ${ }^{6}$ Hanumanth Reddy, ${ }^{7}$ Sachin B Mangalekar
}

\section{ABSTRACT}

Aim: The present study was undertaken to assess the inhibitory effect of guava extracts on Porphyromonas gingivalis and Aggregatibacter actinomycetemcomitans, to assess the time-kill curve of $P$. gingivalis and $A$. actinomycetemcomitans, and to determine the antiproteolytic activity of guava on $P$. gingivalis.

Materials and methods: Kanamycin blood agar was used to isolate $P$. gingivalis and $A$. actinomycetemcomitans. Ethanolic guava extract (EGE) and aqueous guava extract (AGE) were prepared and the inhibitory effects of these extracts for two periodontal pathogens were tested by minimum inhibitory concentration (MIC) and minimum bactericidal concentration (MBC) procedures. Antibacterial activity of guava extracts was determined by well diffusion method. Antiproteolytic activity of guava on protease of $P$. gingivalis was determined by gelatin liquefaction test.

Results: The MIC determined for AGE and EGE was at $75 \mu \mathrm{L} / \mathrm{mL}$ concentration for $P$. gingivalis, whereas EGE exhibited the activity at $75 \mu \mathrm{L} / \mathrm{mL}$ on $P$. gingivalis. The MIC determined for AGE was at $50 \mu \mathrm{L} / \mathrm{mL}$ for $A$. actinomycetemcomitans, whereas MIC determined for EGE was at $3.12 \mu \mathrm{L} / \mathrm{mL}$ for $A$. actinomycetemcomitans. Porphyromonas gingivalis was susceptible to EGE compared with AGE. Aggregatibacter actinomycetemcomitans was more susceptible to guava extracts compared with $P$. gingivalis.

\footnotetext{
${ }^{1-3}$ Department of Periodontics, Pacific Academy of Higher Education and Research University, Udaipur, Rajasthan, India

${ }^{4}$ Department of Preventive and Pediatric Dentistry, College of Dentistry, Gulf Medical University, Ajman, United Arab Emirates

${ }^{5}$ Department of Pharmacology, Vaagdevi College of Pharmacy Warangal, Telangana, India

${ }^{6}$ Department of Orthodontics, Chhattisgarh Dental College \& Research Institute, Rajnandgaon, Chhattisgarh, India

${ }^{7}$ Department of Periodontics, Bharati Vidyapeeth Dental College and Hospital, Sangli Maharashtra, India

Corresponding Author: Raghavendra M Shetty, Department of Preventive and Pediatric Dentistry, College of Dentistry Gulf Medical University, Ajman, United Arab Emirates, Phone: +971563019421, e-mail: raghavendra77@yahoo.com
}

Conclusion: Guava extract may be a potential therapeutic agent for periodontitis as it shows significant activity against both $P$. gingivalis and $A$. actinomycetemcomitans.

Clinical significance: Guava leaves extract can be used as economical and suitable adjuvant to synthetic drugs and can be a potential therapeutic agent for periodontitis.

Keywords: Aggregatibacter actinomycetemcomitans, Antimicrobial, Guava, Porphyromonas gingivalis, Psidium guajava.

How to cite this article: Shetty $Y S$, Shankarapillai $R$, Vivekanandan G, Shetty RM, Reddy CS, Reddy H, Mangalekar SB. Evaluation of the Efficacy of Guava Extract as an Antimicrobial Agent on Periodontal Pathogens. J Contemp Dent Pract 2018;19(6):690-697.

\section{Source of support: Nil}

Conflict of interest: None

\section{INTRODUCTION}

An important trend in the dental microbiological research is the discovery of new methods to eradicate dental plaque biofilms. Dental plaque is one of the principal etiologic factors in development periodontal disease. Plaque, if allowed to accumulate, with no intervention or oral hygiene methods, leads to gingivitis which further progresses to periodontitis. ${ }^{1}$

The current treatment for gingivitis and periodontitis is directed at disruption of plaque maturation and/or reduction of the bacterial load which usually includes professional and homecare mechanical methods for the removal of plaque. ${ }^{2} \mathrm{~A}$ distinct difference exists between composition of supragingival and subgingival plaque. ${ }^{3}$ Supragingival plaque exhibits accumulation of predominantly Gram-positive cocci, whereas subgingival plaque is characterized by flora predominated by Gram-negative anaerobic bacilli, such as $P$. gingivalis, $A$. actinomycetemcomitans, and Fusobacterium nucleatum and have shown 
to be associated with the onset and progression of periodontal disease. $^{2}$

The "battle" against oral biofilm is a challenging task, due to their tendency to persist in spite of treatment. This tendency has been attributed to numerous cell-cell communication pathways, such as quorum-sensing, gene transfer, and intrabiofilm metabolic transaction. ${ }^{4}$ Consequently, biofilm microorganisms can be up to 1000 times more resistant than planktonic bacteria to conventional antimicrobial treatment with antibacterial agents, such as antibiotics or chlorhexidine. ${ }^{5,6}$ In view of the growing ineffectiveness of conventional oral biofilm eradication, the implementation of novel treatments inspired by nature has gained increasing interest. ${ }^{7}$

Ayurveda is an ancient Indian system of medicine which is the rich storehouse of time-tested and effective herbal remedies. In the modern times, there is an enormous awareness and scientific trials on medicinal plants and its formulations.

Psidium guajava is a phytotherapic plant commonly known as guava. It is also known as poor man's apple. ${ }^{8}$ Guava is proven for its antidiarrheal, antimicrobial, antiparasitic, antitussive, hepatoprotective, antioxidant, antigenotoxic, antimutagenic, antiallergic, anticancer, and antihyperglycemic effects. ${ }^{9}$ The leaves of guava have been reported to be used for the maintenance of oral hygiene. ${ }^{10}$

The antibacterial activity against cariogenic bacteria Lactobacillus acidophilus is reported to be as similar to that of chlorhexidine. ${ }^{11}$ The literature on the antimicrobial effect of guava on periodontal pathogens, especially $P$. gingivalis and $A$. actinomycetemcomitans, is very scanty.

Hence, the present study was undertaken to assess the inhibitory effect of guava on $P$. gingivalis and A. actinomycetemcomitans, to assess the time-kill curve of $P$. gingivalis and A. actinomycetemcomitans, and to determine the antiproteolytic activity of guava on $P$. gingivalis.

\section{MATERIALS AND METHODS}

\section{Preparation of Guava Extract}

Young leaves of guava were plucked from the plants in Warangal district of Telangana. Leaves samples were washed with tap water, and treated with Tween 20 to remove surface debris, dried in a shade and were grounded in an electric blender to obtain it as a coarse powder.

\section{Aqueous Guava Extract}

One hundred grams of coarse powdered sample was put into a large beaker and was mixed with $1 \mathrm{~L}$ of deionized distilled water. The mixture was boiled until the final volume became one tenth (1:10) of the original and was then filtered to remove any impurities through a $0.2-\mathrm{mm}$ pore size Whatman filter paper; $1 \mathrm{~mL}$ of the clear crude extracts was dispensed into microcentrifuge tubes $(1 \mathrm{~mL} /$ tube) and dried using the speed vacuum concentrator (HETO) until no further changes in weight were observed. The dried extracts were then stored at $-20^{\circ} \mathrm{C}$ until further use. ${ }^{12}$ Prior to use, all the extracts were diluted with sterile deionized distilled water and mixed to a final concentration of $0.5 \mathrm{mg} / \mathrm{mL}$.

\section{Ethanolic Guava Extract}

Ethanolic extract was prepared by mixing $100 \mathrm{gm}$ of coarse powdered sample with $1 \mathrm{~L}$ of ethanol and was obtained through Soxhlet apparatus. The active ingredients leached out in the solvent in every cycle and were continued for 5 to 6 hours till the extraction was complete. The extract was concentrated using a Rotavapor at $50^{\circ} \mathrm{C}$ and freeze dried using lyophilization, following which the residues were finely grounded, weighed, and stored at $4^{\circ} \mathrm{C}$ until further analysis.

\section{Bacteria and Growth Condition}

The stock culture of periodontal pathogens ( $P$. gingivalis and $A$. actinomycetemcomitans) used in the present study was obtained from Belagavi. Kanamycin blood agar was used to isolate $P$. gingivalis and A. actinomycetemcomitans. Trypticase blood agar base with $5 \%$ sheep blood being the major ingredients, supplemented with yeast extract, hemin, vitamin K1, L-cysteine, and in addition, contained $100 \mathrm{mg} / \mathrm{L}$ of kanamycin.

Subculturing of $P$. gingivalis and $A$. actinomycetemcomitans was done by incubating them at $35^{\circ} \mathrm{C}$ to $37^{\circ} \mathrm{C}$ for 48 to 72 hours. The agar plates were inoculated, placed in the anaerobic jars, and incubated for 48 hours, and reincubated for another 2 to 4 days, so as to allow those slow-growing organisms to form colonies. Porphyromonas gingivalis showed black and mucoid colonies, whereas $A$. actinomycetemcomitans showed tiny, translucent colonies.

\section{Agar Diffusion Procedure}

\section{Inoculum Preparations}

A sterilized straight nichrome wire was used to transfer the colonies from the plates to the brain heart infusion (BHI) broth. The turbidity was visually adjusted with $\mathrm{BHI}$ broth to equal that of a $0.5 \mathrm{McF}$ arland unit turbidity standard which was freshly prepared. Alternatively, the suspension was standardized with a photometric device.

\section{Inoculation of Agar Plate}

After adjusting the inoculum to a $0.5 \mathrm{McF}$ arland unit turbidity standard, a sterile cotton swab was dipped into the inoculums and rotated against the wall of the 
tube above the liquid to remove excess inoculum. Entire surface of kanamycin blood agar plate was swabbed 3 times, rotating plates approximately $60^{\circ}$ between streaking to ensure even distribution. The inoculated plate was allowed to stand for at least 3 minutes but no longer than 15 minutes before punching the wells in the agar plate. Five plates for each microorganism were inoculated.

A hollow tube of $5 \mathrm{~mm}$ diameter was taken and heated. It was pressed on the inoculated agar plate and removed immediately; $75,50,25,12.5,6.25$, and $3.12 \mu \mathrm{L}$ of the $500 \mu \mathrm{L} / \mathrm{mL}$ of AGE and EGE were added into the respective wells on each plate. The plates were incubated within 15 minutes of compound application for 18 to 24 hours at $37^{\circ} \mathrm{C}$ anaerobically. The plates were read only if the lawn of growth was confluent or nearly confluent. The diameter of the inhibition zone was measured to nearest whole millimeter by holding the calipers.

\section{Minimum Inhibitory Concentration Procedure}

The MIC of the AGE and EGE was determined by macrobroth dilution method.

One set of 1 to 10 tubes were labeled; $0.5 \mathrm{~mL}$ of BHI broth was added in tubes labeled from 2 to $10 ; 1 \mathrm{~mL}$ of the test material was taken in the first tube; $0.5 \mathrm{~mL}$ of the guava extract from the first tube was transferred to the second tube containing the BHI broth, mixed well, and $0.5 \mathrm{~mL}$ was serially transferred to the third tube, till the 9th tube; $0.5 \mathrm{~mL}$ was discarded from the 9 th and 10 th tube which served as a control. Thus, guava extract solutions were serially diluted and concentrations at 500, 250, 125, $62.5,31.25,16.6,8.3,4$, and $2 \mathrm{mg} / \mathrm{mL}$ for EGE and $\mu \mathrm{L} / \mathrm{mL}$ for AGE were obtained respectively. The tubes were then inoculated with $0.1 \mathrm{~mL}$ of cultures. The lowest concentration of guava extract that completely inhibited the growth of the organisms was considered as MIC.

\section{Minimum Bactericidal Concentration Procedure}

To determine the MBC, the MIC dilution tubes with no visible growth and the control tube were subcultured onto the respective media and incubated for 24 hours anaerobically at $37^{\circ} \mathrm{C}$ and the colonies were counted on the next day. The organisms grown from the control tube were then compared with the organism grown from the MIC test tubes.

The test was read as follows:

- Similar number of colonies indicated bacteriostatic activity only

- Reduced number of the colonies indicated a partial or slow bactericidal activity

- No growth if the whole inoculum was killed

The MBC was carried out to observe the bactericidal effect of the guava extract against the organism. If there was no growth of microorganisms, then the guava extract was known to have bactericidal effect and if there was growth of microorganisms, then the guava extract was known to have no bacteriostatic effect.

\section{Growth-Kill Assay}

The dilutions were done in a manner similar to that of MIC. Then immediately it was plated and was noted at 0 hour. The dilution tubes were kept in anaerobic jar for $P$. gingivalis and carbon dioxide jar for A. actinomycetemcomitans. At the end of 2 hours again, the first were plated. The same procedure was repeated after 4,6 , and 24 hours. Then, the plates were incubated in either of the jars respectively as per the requirement. After 48 hours of incubation at $37^{\circ} \mathrm{C}$, the plates were removed and the colonies were counted.

\section{Antiproteolytic Activity of Guava on Protease of $\boldsymbol{P}$. gingivalis}

Antiproteolytic activity of guava on protease of $P$. gingivalis was determined by gelatin liquefaction test. Thioglycollate broth with $5 \%$ gelatin in distilled water was used for gelatin liquefaction test and this broth was inoculated with the test culture and guava extract along with positive control (with microorganism) and negative control (without microorganism). It was incubated for 5 days at $37^{\circ} \mathrm{C}$ and the antiproteolytic activity of both AGE and EGE on protease of P. gingivalis was determined.

\section{Statistical Analysis}

The data on various study parameters were obtained and summarized using appropriate statistical measures. The continuous variables in the study, such as zone of inhibition, number of colonies were summarized using mean, median, and standard deviation (SD). One-way analysis of variance was used to analyze the significance of difference of colonies at various time intervals. Post hoc Bonferroni's test was used to determine the pairwise significance of difference in the means of colony formed, if the differences across the time intervals were statistically significant. All the analyses were performed using Statistical Package for the Social Sciences version 20.0 (IBM Corp.) and the statistical significance was tested at $5 \%$ level.

\section{RESULTS}

\section{Antibacterial Activity of Guava Extracts on $P$. gingivalis and $A$. actinomycetemcomitans by Well Diffusion Method}

\section{Porphyromonas gingivalis}

A volume of $75 \mu \mathrm{L}$ of AGE showed $10.4 \pm 0.54 \mathrm{~mm}$ (Table 1 ) and $75 \mu \mathrm{L}$ of EGE showed $15.4 \pm 0.54 \mathrm{~mm}$ (Table 2 ) on P. gingivalis. However, there was no zone of inhibition 
Efficacy of Guava in Periodontitis

Table 1: The antibacterial activity of AGE on $P$. gingivalis

\begin{tabular}{lllllll}
\hline & \multicolumn{5}{c}{ Zone of inhibition $(\mathrm{mm})$} & \\
\cline { 2 - 5 } AGE $(\mu L)$ & 1 & 2 & 3 & 4 & 5 & Mean $\pm S D(\mathrm{~mm})$ \\
\hline 25 & 0 & 0 & 0 & 0 & 0 & 0 \\
50 & 0 & 0 & 0 & 0 & 0 & 0 \\
75 & 10 & 11 & 10 & 10 & 11 & $10.4 \pm 0.54$ \\
\hline
\end{tabular}

Table 3: The antibacterial activity of AGE on $A$. actinomycetemcomitans

\begin{tabular}{lllllll}
\hline \multirow{2}{*}{$\begin{array}{l}\text { Aqueous guava } \\
\text { concentration }(\mu L)\end{array}$} & \multicolumn{6}{l}{ Zone of inhibition $(\mathrm{mm})$} \\
\cline { 2 - 6 } & 1 & 2 & 3 & 4 & 5 & Mean $\pm S D(\mathrm{~mm})$ \\
\hline 25 & 0 & 0 & 0 & 0 & 0 & 0 \\
50 & 18 & 19 & 18 & 17 & 19 & $18.2 \pm 0.83$ \\
75 & 23 & 21 & 23 & 25 & 22 & $22.8 \pm 1.48$ \\
\hline
\end{tabular}

Table 2: The antibacterial activity of EGE on $P$. gingivalis

\begin{tabular}{lllllll}
\hline & \multicolumn{5}{c}{ Zone of inhibition $(\mathrm{mm})$} & \\
\cline { 2 - 6 } $\operatorname{EGE}(\mu L)$ & 1 & 2 & 3 & 4 & 5 & Mean $\pm S D(\mathrm{~mm})$ \\
\hline 25 & 0 & 0 & 0 & 0 & 0 & 0 \\
50 & 0 & 0 & 0 & 0 & 0 & 0 \\
75 & 15 & 16 & 15 & 16 & 15 & $15.4 \pm 0.54$
\end{tabular}

Table 4: The antibacterial activity of EGE on $A$. actinomycetemcomitans

\begin{tabular}{|c|c|c|c|c|c|c|}
\hline \multirow{2}{*}{$\begin{array}{l}\text { Ethanolic guava } \\
\text { concentration }(\mu L)\end{array}$} & \multicolumn{5}{|c|}{ Zone of inhibition ( $\mathrm{mm}$ ) } & \multirow[b]{2}{*}{ Mean $\pm S D(m m)$} \\
\hline & 1 & 2 & 3 & 4 & 5 & \\
\hline 3.12 & 12 & 12 & 11 & 12 & 11 & $11.6 \pm 0.54$ \\
\hline 6.25 & 12 & 12 & 11 & 12 & 12 & $11.8 \pm 0.44$ \\
\hline 12.5 & 13 & 14 & 13 & 14 & 13 & $13.4 \pm 0.54$ \\
\hline 25 & 15 & 15 & 16 & 14 & 15 & $15.0 \pm 0.70$ \\
\hline 50 & 18 & 19 & 17 & 17 & 19 & $18.0 \pm 1.00$ \\
\hline 75 & 20 & 21 & 20 & 19 & 21 & $20.2 \pm 0.83$ \\
\hline
\end{tabular}

Table 5: Minimum inhibitory concentration and MBC of guava extracts on $P$. gingivalis

\begin{tabular}{lllllllllll}
\hline Guava $(\mu L)$ & 500 & 250 & 125 & 62.5 & 31.25 & 16.6 & 8.3 & 4 & 2 & Control \\
\hline MIC of guava on P. gingivalis & & & & & & & & & \\
AGE & $S$ & $S$ & $S$ & $S$ & $S$ & $S$ & $\mathrm{~S}$ & $\mathrm{R}$ & $\mathrm{R}$ & $\mathrm{R}$ \\
EGE & $\mathrm{S}$ & $\mathrm{S}$ & $\mathrm{S}$ & $\mathrm{S}$ & $\mathrm{S}$ & $\mathrm{S}$ & $\mathrm{S}$ & $\mathrm{S}$ & $\mathrm{R}$ & $\mathrm{R}$ \\
$\begin{array}{l}\text { MBC of guava on } P \text {. gingivalis (CFU/mL) } \\
\text { AGE }\end{array}$ & NG & NG & NG & NG & NG & 12 & 23 & 36 & 63 & 102 \\
EGE & NG & NG & NG & NG & NG & 38 & 49 & 58 & 72 & 96 \\
\hline
\end{tabular}

S: Susceptible; R: Resistant; NG: No growth

Table 6: Minimum inhibitory concentration and MBC of guava extracts on $A$. actinomycetemcomitans

\begin{tabular}{lllllllllll}
\hline Guava $(\mu L)$ & 500 & 250 & 125 & 62.5 & 31.25 & 16.6 & 8.3 & 4 & 2 & Control \\
\hline MIC of guava on & A. actinomycetemcomitans & & & & & & & \\
AGE & $\mathrm{S}$ & $\mathrm{S}$ & $\mathrm{S}$ & $\mathrm{S}$ & $\mathrm{S}$ & $\mathrm{R}$ & $\mathrm{R}$ & $\mathrm{R}$ & $\mathrm{R}$ & $\mathrm{R}$ \\
EGE & $\mathrm{S}$ & $\mathrm{S}$ & $\mathrm{S}$ & $\mathrm{S}$ & $\mathrm{S}$ & $\mathrm{S}$ & $\mathrm{S}$ & $\mathrm{S}$ & $\mathrm{S}$ & $\mathrm{R}$ \\
$\begin{array}{l}\text { MBC of guava on } \\
\text { AGE }\end{array}$ & NG actinomycetemcomitans (CFU/mL) & NG & NG & NG & NG & 86 & 102 & 136 & 148 & 162 \\
EGE & NG & NG & NG & NG & NG & NG & NG & NG & NG & 46 \\
\hline
\end{tabular}

S: Susceptible; R: Resistant; NG: No growth

seen for lower concentrations of both AGE and EGE on P. gingivalis.

\section{Aggregatibacter Actinomycetemcomitans}

A volume of $50 \mu \mathrm{L}$ and $75 \mu \mathrm{L}$ of AGE showed $18.2 \pm 0.83$ and $22.8 \pm 1.48 \mathrm{~mm}$ zone of inhibition respectively, on $A$. actinomycetemcomitans (Table 3).

Volumes of $75,50,25,12.5,6.25$, and $3.12 \mu \mathrm{L}$ of EGE showed $20.2 \pm 0.83,18.0 \pm 1.00,15.0 \pm 0.70,13.4 \pm 0.54,11.8$ \pm 0.44 , and $11.6 \pm 0.54 \mathrm{~mm}$ zone of inhibition respectively, on $A$. actinomycetemcomitans (Table 4).

\section{Inhibitory Effect of Guava Extracts}

Further, the antibacterial activity testing of the AGE and EGE by Macrobroth dilution revealed MIC and MBC at different concentrations of the guava extract.

\section{Minimum Inhibitory Concentration and $\mathrm{MBC}$ of Guava Extracts on P. Gingivalis}

The AGE exhibited MIC at $4 \mu \mathrm{L} / \mathrm{mL}$, whereas EGE exhibited MIC at $2 \mu \mathrm{L} / \mathrm{mL}$. In MBC, both AGE and EGE showed similar bactericidal activity against the $P$. gingivalis (Table 5).

\section{Minimum Inhibitory Concentration and MBC of Guava Extracts on A. Actinomycetemcomitans}

Aggregatibacter actinomycetemcomitans showed lesser resistance to ethanolic extracts. The MIC for the AGE was determined at $16.6 \mu \mathrm{L} / \mathrm{mL}$, whereas A. actinomycetemcomitans was completely susceptible to all the concentrations of the EGE. In MBC, the EGE showed greater bactericidal activity than AGE (Table 6). 
Table 7: Time-kill assay for $P$. gingivalis

\begin{tabular}{lllllllll}
\hline & \multicolumn{9}{c}{ Time $($ Hrs $)$} & & & \multicolumn{2}{c}{ Significance $^{*}$} \\
\cline { 2 - 5 } Extracts & 0 & 2 & 4 & 6 & 24 & & $f$-value & $p$-value \\
\hline AGE & 142.2 & 131.4 & 102.4 & 99.6 & 500 & & 71318.961 & $<0.001^{*}$ \\
EGE & 126.0 & 95.8 & 74.6 & 70.0 & 500 & & 28879.908 & $<0.001^{*}$ \\
\hline
\end{tabular}

Post hoc Bonferroni's test: Both AGE and EGE for 4 vs 6 hours, nonsignificant; *Significant

Table 8: Time-kill assay for $A$. actinomycetemcomitans

\begin{tabular}{|c|c|c|c|c|c|c|c|}
\hline \multirow[b]{2}{*}{ Extracts } & \multicolumn{5}{|c|}{ Time (Hrs) } & \multicolumn{2}{|c|}{ Significance* } \\
\hline & 0 & 2 & 4 & 6 & 24 & $f$-value & $p$-value \\
\hline AGE & 132.0 & 98.2 & 72.4 & 101.6 & 500 & 85394.201 & $<0.001^{*}$ \\
\hline EGE & 128.2 & 92.6 & 86.4 & 84.4 & 500 & 23372.979 & $<0.001^{*}$ \\
\hline
\end{tabular}

Post hoc Bonferroni's test: AGE 2 vs 6 hours, nonsignificant; EGE 2 vs 4 hours, 2 vs 6 hours, 4 vs 6 hours, nonsignificant; *Significant

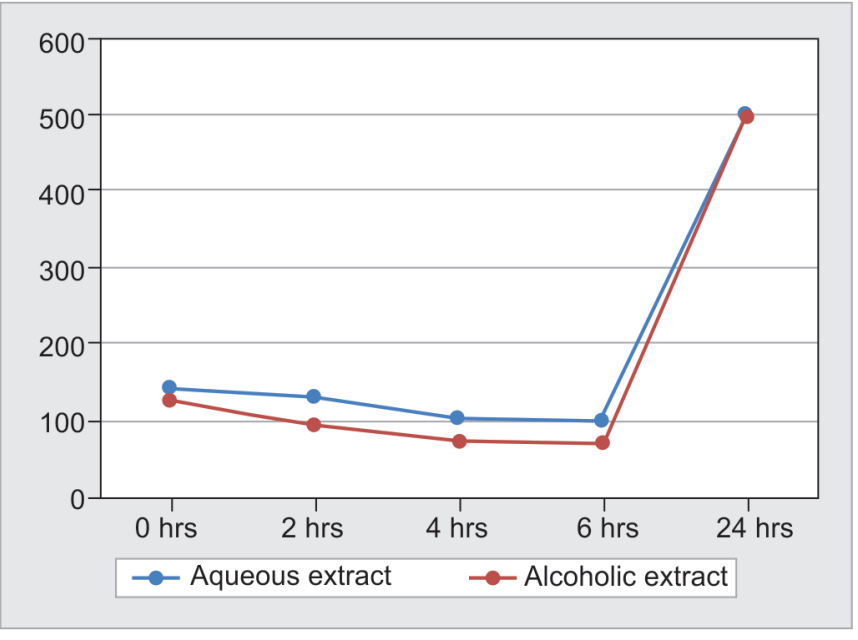

Graph 1: Time-kill assay for $P$. gingivalis

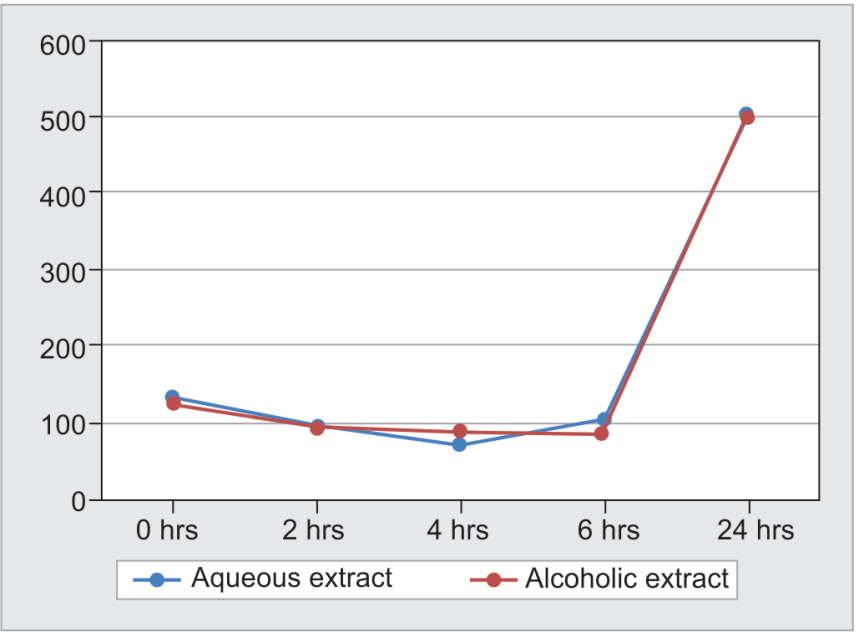

Graph 2: Time-kill assay for $A$. actinomycetemcomitans

Table 9: Effect of guava on $P$. gingivalis protease activity

\begin{tabular}{llllll}
\hline \multicolumn{5}{c}{ RGE $(\mu L)$} & \multicolumn{1}{c}{$E G E(\mu L)$} \\
\hline 500 & 250 & 125 & 500 & 250 & 125 \\
$\begin{array}{l}\text { No inhibition of } \\
\text { liquefaction }\end{array}$ & $\begin{array}{l}\text { No inhibition of } \\
\text { liquefaction }\end{array}$ & $\begin{array}{l}\text { No inhibition of } \\
\text { liquefaction }\end{array}$ & $\begin{array}{l}\text { No inhibition of } \\
\text { liquefaction }\end{array}$ & $\begin{array}{l}\text { No inhibition of } \\
\text { liquefaction }\end{array}$ & $\begin{array}{l}\text { No inhibition of } \\
\text { liquefaction }\end{array}$ \\
\hline
\end{tabular}

\section{Time-kill Assay}

The time-kill assay was also performed on $P$. gingivalis and A. actinomycetemcomitans in the presence of guava extracts at their respective MICs. Statistically significant decrease in the colonies of $P$. gingivalis was seen up to 6 hours in both AGE and EGE. Bacteriostatic activity was seen during 4 to 6 hours in case of both types of guava extracts where there was no statistically significant difference in the colonies count from 4 to 6 hours. There was increase in the colony-forming units with no bacteriostatic activity at 24 hours (Table 7 and Graph 1). Control cell suspensions without guava extract showed no drop in viability over the same period.

The A. actinomycetemcomitans colonies count decreased statistically up to 4 hours with aqueous extract and there was increase in the colony-forming units with no bacteriostatic activity at 6 and 24 hours. However, with ethanolic extract, there was statistically significant decrease in the colonies count up to 6 hours with no significant difference from 2 to 6 hours indicating bacteriostatic activity between 2 and 6 hours (Table 8 and Graph 2). Control cell suspensions without guava extract showed no drop in viability over the same period.

\section{Antiproteolytic Activity of Guava Extracts on P. Gingivalis}

Aqueous and ethanolic extracts of guava did not show any antiproteolytic activity on total protease of $P$. gingivalis in gel liquefaction test (Table 9).

\section{DISCUSSION}

Antimicrobial resistance, considerable side effects, and the emergence of previously uncommon infections are the results of improper usage of synthetic antimicrobial 
agents. ${ }^{13}$ Instead, plant chemicals are one of the most powerful and safe alternative chemotherapeutic agents to control many infections if they are supported by scientificbased evidence. ${ }^{14}$ Recently, there is an increasing interest to investigate the effect of natural compounds, especially plant extracts, on the residence of the oral cavity. Many of the investigations have been focused on the ability of the compound to either promote the growth of beneficial organisms or inhibit the growth and metabolism of oral bacteria associated with certain diseases. ${ }^{12}$

Periodontal disease is an infectious process ranging in severity from mild gingivitis to advanced loss of connective tissue attachment and supporting bone. ${ }^{15}$ Scaling and root planing is a traditional method that has been shown to be an effective treatment for chronic periodontitis. Although mechanical treatment significantly decreases the prevalence and levels of subgingival microorganisms, it does not necessarily eliminate all pathogens. ${ }^{16}$ The successful treatment of periodontitis requires suppression or elimination of the subgingival periodontal pathogens. The efficacy of nonsurgical mechanical procedures and conventional home care in controlling the pathogenic flora decreases as probing depth increases. Thereby, antimicrobial agents attempt to directly reduce the pocket microflora when applied as an adjunct to mechanical debridement. ${ }^{17}$

Guava is proven for its antidiarrheal, antimicrobial, ${ }^{18-22}$ antiparasitic, ${ }^{23}$ antitussive, ${ }^{24,25}$ antigenotoxic, antimutagenic, antiallergic, ${ }^{26,27}$ anthelmintic, ${ }^{28}$ hepatoprotective, and antioxidant properties. ${ }^{29}$ It is also reported that it can be beneficial in oral diseases like periodontitis ${ }^{30-32}$ and gingivitis. ${ }^{33}$ The present study assessed the activity of guava, particularly against putative periodontal pathogens. Collectively, the putative periodontal pathogens tested were $A$. actinomycetemcomitans and P. gingivalis. The inhibitory effect of AGE and EGEs on $P$. gingivalis and $A$. actinomycetemcomitans was evaluated using agar well diffusion, MIC, MBC, and the time-kill profile. The antiproteolytic activity of AGE and EGEs on P. gingivalis was also evaluated in the present study.

The AGE showed inhibition of growth of $P$. gingivalis with $10.4 \pm 0.54 \mathrm{~mm}$ zone of inhibition and EGE showed 15 $\pm 0.54 \mathrm{~mm}$ zone of inhibition for P. gingivalis at $75 \mu \mathrm{L} / \mathrm{mL}$ concentration. However, there was no zone of inhibition seen for lower concentrations of both AGE and EGE on P. gingivalis; 50 and $75 \mu \mathrm{L}$ of AGE showed $18.2 \pm 0.83$ and $22.8 \pm 1.48 \mathrm{~mm}$ zone of inhibition respectively, on A. actinomycetemcomitans. However, there was no zone of inhibition seen for lower concentrations of AGE on A. actinomycetemcomitans, whereas EGE showed zone of inhibition even for the lower concentrations of $3.12 \mu \mathrm{L}$ on A. actinomycetemcomitans.

Porphyromonas gingivalis showed better inhibition to EGE compared with AGE. Aggregatibacter actinomycetemcomitans also showed better inhibition to EGE compared with AGE in well diffusion method. Analysis of these data revealed that $P$. gingivalis was susceptible to EGE compared with AGE. These data also revealed that $A$. actinomycetemcomitans is more susceptible to guava extracts compared with $P$. gingivalis. This may be due to the structural differences between both the organisms.

Guava extracts showed bacteriostatic activity on P. gingivalis and A. actinomycetemcomitans. The MIC determined for AGE and EGE was at $75 \mu \mathrm{L} / \mathrm{mL}$ concentration for $P$. gingivalis, whereas EGE exhibited the activity at $75 \mu \mathrm{L} / \mathrm{mL}$ on $P$. gingivalis. The MIC determined for AGE was at $50 \mu \mathrm{L} / \mathrm{mL}$ for $A$. actinomycetemcomitans, whereas MIC determined for EGE was at $3.12 \mu \mathrm{L} / \mathrm{mL}$ for $A$. actinomycetemcomitans in well diffusion method. This difference probably may be indicative of constituents of guava binding to constituents in the agar medium limiting the diffusion. Hence, MIC values obtained using the broth dilution methods were considered more reliable. ${ }^{34}$

The AGE exhibited MIC at $4 \mu \mathrm{L} / \mathrm{mL}$, whereas EGE exhibited MIC at $2 \mu \mathrm{L} / \mathrm{mL}$ for $P$. gingivalis. In MBC, both AGE and EGE showed similar bactericidal activity against the P. gingivalis. Aggregatibacter actinomycetemcomitans showed lesser resistance to ethanolic extracts. The MIC for the AGE was determined at $16.6 \mu \mathrm{L} / \mathrm{mL}$, whereas A. actinomycetemcomitans was completely susceptible to all the concentrations of the EGE. In MBC, the ethanolic extracts showed greater bactericidal activity than the aqueous extracts. MIC values of guava extract were lower in $A$. actinomycetemcomitans compared with $P$. gingivalis in the present study.

Biswas et $\mathrm{al}^{35}$ concluded from their study that the guava plant extracts have no antibacterial effect on the Gram-negative bacteria (Escherichia coli and Salmonella enteritidis), but observed antibacterial effect on Grampositive bacteria (Bacillus cereus and Staphylococcus aureus). In contrast, Gitika and $\mathrm{Kumar}^{36}$ reported that guava extract showed antibacterial effect on both Grampositive (Micrococcus luteus, Bacillus subtilis, S. aureus, and Streptococcus sp.) and Gram-negative bacteria (E. coli, Pseudomonas aeruginosa, and Salmonella typhimurium). However, in the present study, both AGE and EGE exhibited bacteriostatic and bactericidal activity against the Gram-negative microorganisms (A. actinomycetemcomitans and $P$. gingivalis) used in the study.

The time-kill assay was performed on $P$. gingivalis and $A$. actinomycetemcomitans in the presence of garlic extracts at their respective MBCs and MICs. Statistically significant decrease in the colonies of $P$. gingivalis was seen up to 6 hours in both AGE and EGEs. Bacteriostatic activity was seen during 4 to 6 hours in case of both types of guava extracts, whereas there was no statistically 
significant difference in the colonies count from 4 to 6 hours. There was an increase in the colony-forming units with no bacteriostatic activity at 24 hours. The A. actinomycetemcomitans colonies count decreased statistically up to 4 hours with aqueous extract and there was an increase in the colony-forming units with no bacteriostatic activity at 6 and 24 hours. However, with ethanolic extract, there was statistically significant decrease in the colonies count up to 6 hours with no significant difference from 2 to 6 hours indicating bacteriostatic activity present between 2 and 6 hours. These observations suggested that the guava extract elicited its antimicrobial potency in a timedependent manner producing distinct time-kill profiles, suggesting variations in the growth inhibitory responses of the tested isolates to guava. However, the uniqueness of time-kill profiles on Gram-negative microbes in this study may be connected with the structural difference between these two organisms.

In the present study, AGE and EGE did not show any antiproteolytic activity on total protease of $P$. gingivalis in gel liquefaction test, suggesting that guava leaf extract does not act on the cysteine protease (gingipains) of $P$. gingivalis.

In the present study, AGE and EGE were more efficacious on $A$. actinomycetemcomitans compared with $P$. gingivalis. This may be due to the reason that guava leaf extract does not show any antiproteolytic activity on proteases of $P$. gingivalis, whereas guava extract may have shown neutralization of leukotoxin of A. actinomycetemcomitans, which is one of the major endotoxins causing periodontal disease. ${ }^{37}$ The efficacy of ethanolic guava leaf extract was found to be better than aqueous guava leaf extract. Ethanolic extract contains tannins as well as flavonoids, whereas aqueous extract contains tannins but not flavonoids. This difference in composition of ethanolic and aqueous extract can be attributed to the difference in the solubility of various components of guava leaves in water and organic solvents. ${ }^{22}$

This study suggests that guava extract may be a potential therapeutic agent for periodontitis because it shows significant activity against both $P$. gingivalis and $A$. actinomycetemcomitans. However, to translate into effective in vivo therapies for periodontitis, therapeutic agents must ideally be active against biofilms rather than just planktonic cells. The present study evaluated qualitatively the antimicrobial potential of guava leaves extract against periodontal pathogens. It is recommended that the readily accessible natural products may be integrated with presently available synthetic materials that are used to maintain the oral hygiene.

Although the guava leaf extract used in this study is not known to have side effects, oral retention and duration of action of these phytoplants are important factors that need further exploration. Any natural product should be assessed for its safety and clinical application should not be done without sufficient scientific evidence. Thus, further quantitative research is needed to know the antimicrobial activity and to evaluate the effectiveness and safety of guava extracts in vivo.

\section{CONCLUSION}

With the rise in bacterial resistance to antibiotics, there is considerable interest in the development of other classes of antimicrobials for the control of infection. Guava has been used as a medicine since ancient times and has long been known to have antimicrobial, antidiarrheal, antiparasitic, antitussive, antigenotoxic, antimutagenic, antiallergic, anthelmintic, hepatoprotective, and antioxidant properties.

From the current study, it can be concluded that there is preliminary evidence for the antimicrobial activity of guava extracts against periodontal pathogens $A$. actinomycetemcomitans and $P$. gingivalis. Hence, guava leaves extract can be used as economical and suitable adjuvant to synthetic drugs and can be a potential therapeutic agent for periodontitis.

\section{REFERENCES}

1. BansalS, RastogiS, Bajpai M. Mechanical, chemical and herbal aspects of periodontitis: a review. Int J Pharm Sci Res 2012 May;3(5):1260-1267.

2. Perinetti G, Paolantonio M, Cordella C, D'Ercole S, Serra E, Piccolomini R. Clinical and microbiological effects of subgingival administration of two active gels on persistent pockets of chronic periodontitis patients. J Clin Periodontol 2004 Apr;31(4):273-281.

3. Takarada K, Kimizuka R, Takahashi N, Honma K, Okuda K, Kato T. A comparison of the antibacterial efficacies of essential oils against oral pathogens. Oral Microbiol Immunol 2004 Feb;19(1):61-64.

4. Kolenbrander PE, Palmer RJ Jr, Periasamy S, Jakubovics NS. Oral multispecies biofilm development and the key role of cell-cell distance. Nat Rev Microbiol 2010 Jul;8(7):471-480.

5. Welin-Neilands J, Svensäter G. Acid tolerance of biofilm cells of Streptococcus mutans. Appl Environ Microbiol 2007 Sep;73(17):5633-5638.

6. Karygianni L, Ruf S, Follo M, Hellwig E, Bucher M, Anderson AC Vach K, Al-Ahmad A. Novel broad-spectrum antimicrobial photoinactivation of in situ oral biofilms using visible light plus water-filtered infrared A. Appl Environ Microbiol 2014 Dec;80(23):7324-7336.

7. Paddon CJ, Westfall PJ, Pitera DJ, Benjamin K, Fisher K, Mcphee D, Leavell MD, Tai A, Main A, Eng D, et al. Highlevel semi-synthetic production of the potent antimalarial artemisinin. Nature 2013 Apr;496(7446):528-532.

8. Ismail M, Minhas PS, Khanum F, Sahan VM, Sowmya C. Antibacterial activity of leaves extract of guava (Psidium guajava). Int J Res Pharm Biomed Sci 2012 Jan;3(1):1-2.

9. Gupta GK, Chahal J, Arora D. Psidium guajava Linn: current research and future prospects. J Pharm Res 2011 Jan 4(1):42-46. 
10. Jebashree HS, Kingsley SJ, Sathish ES, Devapriya D. Antimicrobial activity of few medicinal plants against clinically isolated human cariogenic pathogens-an in vitro study. ISRN Dent 2011 Jun;2011:541421.

11. Jain D, Dasar P, Nagarajappa S, Kumar S, Airen B, Warhekar S. In vitro activity of ethanolic and water extract of guava leaves at various concentrations against Lactobacillus acidophilus. J Indian Assoc Public Health Dent 2014 Nov;12(3):232-236.

12. Wan Nordini Hasnor WI, Fathilah AR, Rahim ZH. Plant extracts of Psidium guajava, Mangifera and Mentha sp. inhibit the growth of the population of single-species oral biofilm. Altern Integ Med 2013 Jan;2(1):1000102.

13. Li M, Xu Z. Quercetin in a lotus leaves extract may be responsible for antibacterial activity. Arch Pharm Res 2008 May;31(5):640-644.

14. Mehta VV, Rajesh G, Rao A, Shenoy R, Mithun Pai BH. Antimicrobial efficacy of Punica granatum mesocarp, Nelumbo nucifera leaf, Psidium guajava leaf and Coffea canephora extract on common oral pathogens: an in-vitro study. J Clin Diagn Res 2014 Jul;8(7):ZC65-ZC68.

15. Jorgensen MG, Slots J. The ins and outs of periodontal antimicrobial therapy. J Calif Dent Assoc 2002 Apr;30(4):297-305.

16. Shetty S, Thomas B, Shetty V, Bhandary R, Shetty RM. An in-vitro evaluation of the efficacy of garlic extract as an antimicrobial agent on periodontal pathogens: a microbiological study. Ayu 2013 Oct;34(4):445-451.

17. Fine JB, Harper DS, Gordon JM, Hovliaras CA, Charles CH. Short-term microbiological and clinical effects of subgingival irrigation with anantimicrobial mouthrinse. J Periodontol 1994 Jan;65(1):30-36.

18. Tribhuvan S, Khobragade Deepak S. Synthesis and evaluation of thiazolidine-4-one for their antibacterial activity. J Pharm Sci Bio Res 2014 Mar;4(1):110-113.

19. Tribhuvan S, Brijendra KS, Vishanu Vardhan Reddy B, Bhandarkar S. Synthesis characterization and pharmacological activity of novel pyrimidine analogues. Int J Pharm Sci Rev Res 2011 Nov-Dec;11(1):110-114.

20. Alviano DS, Alviano CS. Plant extracts: search for new alternatives to treat microbial diseases. Curr Pharm Biotechnol 2009 Jan;10(1):106-121.

21. Tribhuvan S, Lavanya R, Shrikanth M, Sudhakar P. Synthesis characterization and biological activity of some aryl and hetroarylchalcone analogues. Int Res J Pharm 2012;3(7):254-256.

22. Cowan MM. Plant products as antimicrobial agents. Clin Micro Rev 1999 Oct;12(4):564-582.

23. Tribhuvan S, Khobragade Deepak S. Synthesis of thiazolidine4-one for their anthelmintic activity. Uni J Pharm Bio Sci 2014 Jan-Feb;2(1):13-15.
24. Jaiarj P, Khoohaswan P, Wongkrajang Y. Peungvicha P, Suriyawong P, Saraya ML, Ruangsomboon O. Anticough and antimicrobial activities of Psidium guajava linn leaf extract. J Ethnopharmacol 1999 Nov;67(2):203-212.

25. Esimone CO, Nworu CS, Ekong US, Iroha IR, Okolin CS. A case for the use of herbal extracts in oral hygiene the efficacy of Psidium guajava based mouthwash formulations. Res J Appl Sci 2007 Jan;2(11):1143-1149.

26. Joseph B, Priya RM. Phytochemical biopharmaceutical aspects of Psidium guajava and essential oil. Rev Res J Med Plant 2011 Apr;5(4):432-442.

27. Tribhuvan S, Narendra Sharath Chandra JN, Ravi Kumar V, Shruthi J, Sharvani Y. In vitro anthelmintic activity on Guru Nanak chyawanprash. J Pharm Sci Bio Res 2015;5(5): 444-446.

28. Singh T, Kumar D, Samal HB, Sudhakar P. Synthesis characterization and pharmacological activity of novel thiadiazole analogues. Int Res J Pharm 2012;3(4):390-394.

29. Tribhuvan S, Brijendra KS, Vishanu Vardhan Reddy B. Synthesis and evaluation of thiazilidinones derivatives for their pharmacological activity. Int J Res Pharm Bio Sci 2011;2(4):1562-1567.

30. Kornman KS. Mapping the pathogenesis of periodontitis: a new look. J Periodontol 2008 Aug;79(8 Suppl):1560-1568.

31. Kumar P, Ansari SH, Ali J. Herbal remedies for the treatment of periodontal disease: a patent review. Recent Pat Drug Deliv Formul 2009 Nov;3(3):221-228.

32. Shetty S, Vivekanandan G, Patil S, Mangalekar SB. Psidium guajava: a potential adjunct in the management of periodontal diseases-a review. Int J Innov Dent Sci 2017 Aug;2(2): 5-14.

33. Somu CA, Ravindra S, Ajith S, Ahamed MG. Efficacy of a herbal extract gel in the treatment of gingivitis: a clinical study. J Ayurveda Integr Med 2012 Apr;3(2):85-90.

34. Bakri IM, Douglas CW. Inhibitory effect of garlic extract on oral bacteria. Arch Oral Biol 2005 Jul;50(7):645-651.

35. Biswas B, Rogers K, McLaughlin F, Daniels D, Yadav A. Antimicrobial activities of leaf extracts of guava (Psidium guajava L.) on two Gram-negative and Gram-positive bacteria. Int J Microbiol 2013 Oct;2013:746165.

36. Gitika, Kumar M. Antibacterial activity of Psidium guajava L. leaves extracts against some gram-positive and gram-negative bacteria. Eur J Pharm Med Res 2016 Oct; 3(10):261-266

37. Kwamin F, Gref R, Haubek D, Johansson A. Interactions of extracts from selected chewing stick sources with Aggregatibacter actinomycetemcomitans. BMC Res Notes 2012 Jul;5:203. 